\title{
Advanced Breast Angiosarcoma Completely Responding to Chemotherapy
}

\author{
Zhiguo Luo $^{1 *}$, Qian Wang ${ }^{2 *}$, Wei Peng ${ }^{1}$, Jianhua Chang ${ }^{1}$, Xichun Hu ${ }^{1}$, Xiaonan Hong ${ }^{1 \#}$ \\ ${ }^{1}$ Department of Medical Oncology, Fudan University Shanghai Cancer Center, Shanghai, China; ${ }^{2}$ Department of Oncology, Shanghai \\ Xuihui District Hospital, Shanghai, China. \\ Email: \#xnhong@126.com
}

Received March 28 ${ }^{\text {th }}$, 2013; revised April 29 ${ }^{\text {th }}, 2013$; accepted May $8^{\text {th }}, 2013$

Copyright (c) 2013 Zhiguo Luo et al. This is an open access article distributed under the Creative Commons Attribution License, which permits unrestricted use, distribution, and reproduction in any medium, provided the original work is properly cited.

\begin{abstract}
Introduction: For patients with anthracycline-resistant metastatic angiosarcoma, currently there is no available standard for second-line therapy and there is a need for novel effective regimens to improve response rates. Case report: We reported here about a case of a primary angiosarcoma of both breasts in a 34-year-old woman presenting lung metastases. At the completion of 3 cycles of the MAID regimen including mesna, adriamycin, ifosfamide and dacarbazine, CT showed progression of the disease (PD). Subsequently second-line chemotherapy was started using GVP regimen consisting of gemcitabine, vincristine and cisplatin. Complete response (CR) of the lung metastases was achieved after 6 treatment cycles. Conclusion: In the absence of an effective therapy among patients with anthracycline-resistant metastatic breast angiosarcoma, a GVP chemo-regimen can be performed as a selective option.
\end{abstract}

Keywords: Angiosarcoma; Lung Metastases; Gemcitabine; Chemotherapy

\section{Introduction}

Primary angiosarcoma of the breast is a rarely highly aggressive malignancy and it accounts for about $0.05 \%$ of malignant breast neoplasms [1,2]. The 3 years diseasefree survival (DFS) and overall survival (OS) are 14\% and 38\% respectively [3]. Bilateral primary breast angiosarcoma is even more infrequent. A case of metachronous bilateral angiosarcoma of the breast was once reported [4]. We here reported about a complete remission of anthracycline resistant lung metastases of a bilateral primary angiosarcoma of the breast using GVP chemo-regimen.

\section{Case Report}

A 34-year-old female was referred to our hospital on 14th July, 2009. She had noticed diffuse enlargement of bilateral breast by more than one-third over the past 1 -year period with erythematous infiltrated areas of surface gradually developing to $6 \mathrm{~cm}$ in diameter in the right breast within 8 months and $3 \mathrm{~cm}$ in diameter in the left breast within 3 months. There were nipple retraction, occasional galactorrhea, local skin thickening and rough-

${ }^{*}$ Contributed equally.

"Corresponding author. ness. The pain was severe but not associated with menstruation. Her previous medical and surgical history was unremarkable.

On physical examination, there were two clearly defined $6 \mathrm{~cm}$ and $3 \mathrm{~cm}$ erythema $1 \mathrm{~mm}$ towering above the skin in the upper outer quadrant of right and left breast respectively. The breasts were diffusely swollen with cutaneous hypertonicity and nipple retraction. There were no associated ulcerated lesions or nipple suffusions. On palpation, the breasts were felt solid with large lumps occupying almost the whole breast and adherent to the skin with limited mobility. The patient denied operation or radiation exposure on the breast before.

Core needle biopsy was taken on the right breast and a possible angiosarcoma was diagnosed. On immunostaining (2009-09148), the tumor cells were positive for Factor VIII, CD31, Vimentin, Ki-67 (+, 30\%) and negative for SMA, CD68, AE1/AE3 and CAM5.2, indicating an endothelial nature. A bilateral simple mastectomy had been performed on 28th July, 2009. Postmastectomy pathology confirmed a poorly differentiated bilateral breast angiosarcoma (Figures 1 and 2). Tumor dimensions on macroscopic examination were $10.0 \times 6.0 \times 3.0 \mathrm{~cm}$ for the left breast and $14.0 \times 9.0 \times 4.0 \mathrm{~cm}$ for the right breast. The nipple dermis and subcutaneous tissue were focally 


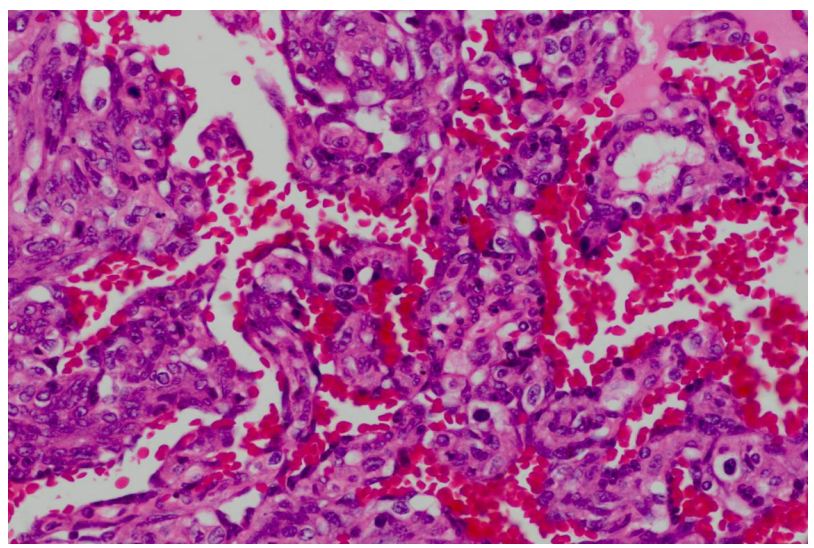

Figure 1. Atypical endothelial cells with numerous mitotic figures and hyperchromatic nuclei lined the vascular structures $(\mathrm{H} \& \mathrm{E} \times \mathbf{4 0 0})$.

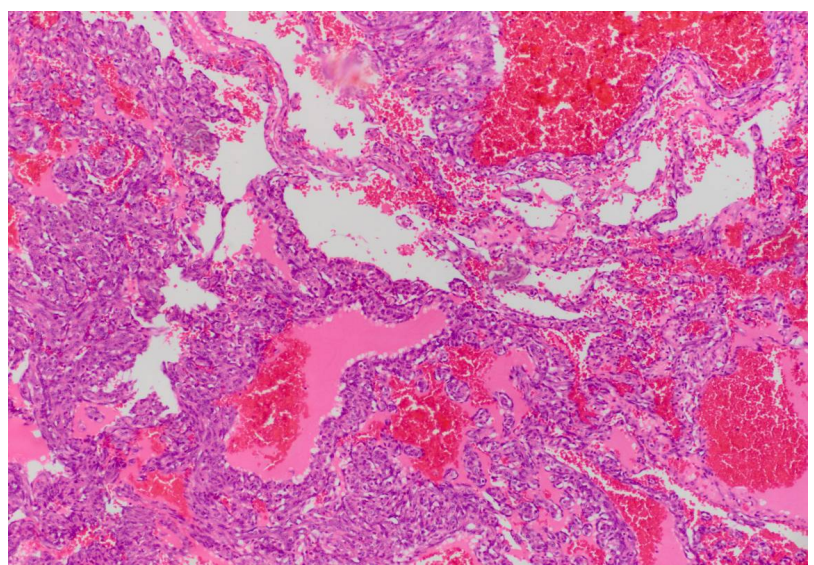

Figure 2. Tumor poorly differentiated with area of necrosis and massive hemorrhages $(\mathrm{H} \& \mathrm{E} \times 200)$.

involved. The tumor was close to the inferior margin with only $0.2 \mathrm{~cm}$ clearance.

Three months after surgery, a CT scan with contrast enhancement revealed a high-density mass in the right lung field on 8th November, 2009 (Figure 3). For palliative therapy, a combinational chemotherapy of MAID regimen was initiated. After 3 cycles treatment the CT for reevaluation showed progression of the disease (PD). Subsequently the patient received GVP chemo-regimen as a salvage therapy. Doses and administration schedule were as follows: gemcitabine $\left[1000 \mathrm{mg} / \mathrm{m}^{2}\right.$ body surface area (BSA)] over 30 minutes on day 1 and 8 , vincristine $\left(1.4 \mathrm{mg} / \mathrm{m}^{2} \mathrm{BSA}\right)$ at most $2 \mathrm{mg}$ on day 1 and cisplatin (25 $\mathrm{mg} / \mathrm{m}^{2} \mathrm{BSA}$ ) from day 1 to 3 . The protocal was repeated at 3-week intervals. After 2 and 4 cycles the CT for control showed gradually smaller-sized metastatic lesions on the right lung field up to a partial remission (PR). A clinical CR was evident after 6 treatment cycles in March 2010 (Figure 4).

In the further follow up the patient developed a $1 \times 0.6$ $\mathrm{cm}$ discolored skin nodule on the right chest wall in June

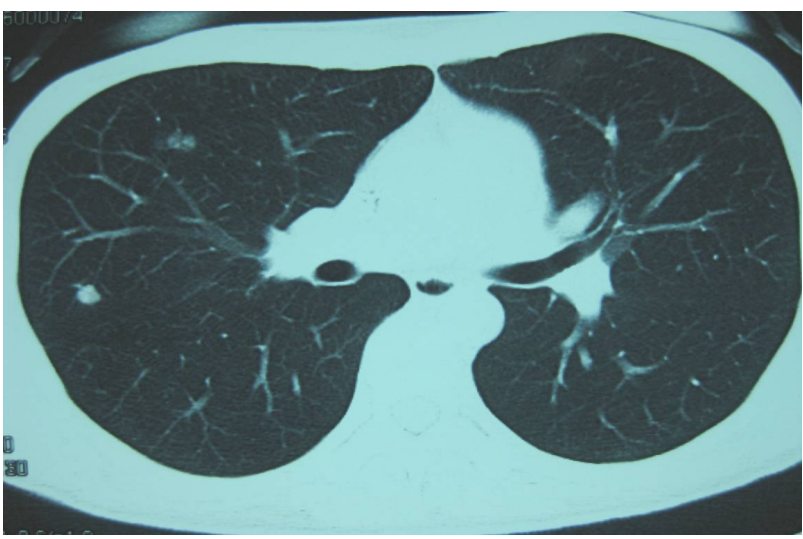

Figure 3. CT scan during the first presentation $\left(8^{\text {th }}\right.$ November, 2009) before chemotherapy shows the pulmonary metastasis.

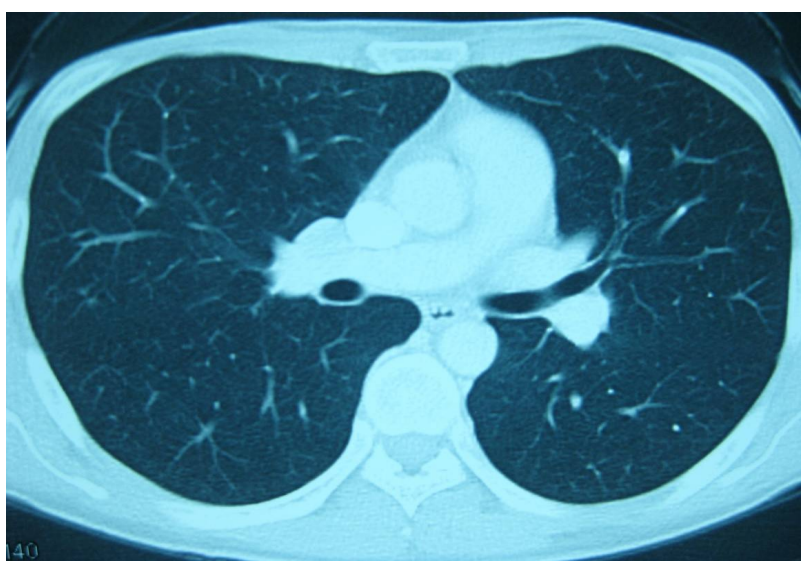

Figure 4. After 6 cycles of GVP chemotherapy $\left(29^{\text {th }}\right.$ March, 2010) the CT scan revealed the complete disappearance of the lung lesions.

2010. A local surgical excision was taken and the histological findings were featured by poorly differentiated vascular endothelial cells, which indicated a metastatic relapse. Then she was given $200 \mathrm{mg}$ thalidomide very day until an enlargement of the skin nodule on the right chest wall was observed on 19th October, for which she was treated with local radiotherapy ended on 6th December.

She had received sunitinib $37.5 \mathrm{mg}$ therapy every day since 12th April after multitude subcutaneous nodules on the waist and back were found and finally died on 30th May, 2011.

\section{Discussion}

Breast angiosarcomas are very rare and they intend to affect women in the third and fourth decades of life with a mean age of 38 years old. Half of patients are probably misdiagnosed due to the scarcity and clinical similarity with benign lesions. A typical clinical manifestation is a rapidly enlarging painless mass deeply embedded in the 
breast tissue. $12 \%$ patients present with initial diffuse enlargement and blocks of calescence of the suffering breast. Some cases with persistent subcutaneous bleeding tend to be ignored as the tumor may be masked. A purple discoloration of the overlying skin by tumor infiltrating is frequent, however the underlying muscle involvement is rare [1,3,5].

Breast angiosarcomas are aggressive as they tend to recur locally and metastasize widely. They mainly spread hematogenously while lymphatic metastasis is generally absent. The most frequent sites of distant metastasis are lung, liver, bone and skin [3]. The prognosis is generally poor and based primarily on tumor size, tumor grade, the completeness of surgery and performance status. Angiosarcomas secondary to irradiation, local relapses and distant metastases are adverse prognostic indicators [4,6-8].

Surgical resection is recommended as the primary treatment. Adjuvant radiotherapy and chemotherapy are considered helpful to reduce local recurrence rate in poorly differentiated tumors [9] but a real effect on survival is not proven. Palliative chemotherapy is the basic concept of treatment in advanced disease. Anthracycline-based regimens have emerged, by consensus, the standard first line therapy for angiosarcomas as well as most other subtypes of soft tissue sarcomas [6]. Paclitaxel and liposomal doxorubicin have also shown some activity [10]. There is still no general agreement about a standardized therapy in patients progressed on an anthracycline. It is reported that trofosfamide plus gemcitabine are feasible and can be safely administered [11]. Besides, docetaxel has also been demonstrated as an effective agent [12]. Capecitabine alone or combined with docetaxel also has some effect [13-16].

However the efficacy of these regimens is limited and only a few patients can benefit from the second-line treatment [17]. In the reported case we used a GVP regimen after 3 cycles of MAID chemotherapy failure, and a complete remission of the lung metastases was achieved at the completion of 6 cycles treatment.

In summary the GVP regimen seems to be an option as a second-line treatment modality for anthracycline-resistant breast angiosarcomas. More trials are needed to confirm its clinical value.

\section{REFERENCES}

[1] R. M. Donnell, P. P. Rosen, P. H. Lieberman, et al., "Angiosarcoma and Other Vascular Tumors of the Breast," American Journal of Surgical Pathology, Vol. 5, 1981, pp. 629-642. doi:10.1097/00000478-198110000-00005

[2] A. Luini, G. Gatti, J. Diaz, et al., “Angiosarcoma of the Breast: The Experience of the European Institute of Oncology and a Review of the Literature," Breast Cancer Research and Treatment, Vol. 105, No. 1, 2007, pp. 81-85. doi:10.1007/s10549-006-9429-z
[3] K. T. Chen, D. D. Kirkegaard and J. J. Bocian, “Angiosarcoma of the Breast,” Cancer, Vol. 46, No. 2, 1980, pp. 368-371.

doi:10.1002/1097-0142(19800715)46:2<368::AID-CNCR 2820460226>3.0.CO;2-E

[4] S. A. Zhou, H. Wei and K. Ding, "A Rare Case of Metachronous Bilateral Angiosarcoma of the Breast,” Breast Care (Basel), Vol. 4, No. 6, 2009, pp. 405-407. doi:10.1159/000261506

[5] M. J. Merino, D. Carter and M. Berman, “Angiosarcoma of the Breast," American Journal of Surgical Pathology, Vol. 7, No. 1, 1983, pp. 53-60. doi:10.1097/00000478-198301000-00005

[6] M. Van Glabbeke, A. T. van Oosterom, J. W. Oosterhuis, et al., "Prognostic Factors for the Outcome of Chemotherapy in Advanced Soft Tissue Sarcoma: An Analysis of 2185 Patients Treated with Anthracycline-Containing First-Line Regimens-A European Organization for Research and Treatment of Cancer Soft Tissue and Bone Sarcoma Group Study,” Journal of Clinical Oncology, Vol. 17, 1999, pp. 150-157.

[7] T. Sher, B. T. Hennessy, V. Valero, et al., "Primary Angiosarcomas of the Breast," Cancer, Vol. 110, No. 1, 2007, pp. 173-178. doi:10.1002/cncr.22784

[8] P. P. Rosen, M. Kimmel and D. Ernsberger, "Mammary Angiosarcoma. The Prognostic Significance of Tumor Differentiation,” Cancer, Vol. 62, No. 10, 1988, pp. 21452151.

doi:10.1002/1097-0142(19881115)62:10<2145::AID-CN CR2820621014>3.0.CO;2-O

[9] L. R. Silverman, L. Deligdisch, J. Mandeli, et al., "Chemotherapy for Angiosarcoma of the Breast: Case Report of 30-Year Survival and Analysis of the Literature," Cancer Investigation, Vol. 12, No. 2, 1994, pp. 145-155. doi:10.3109/07357909409024870

[10] K. M. Skubitz and P. A. Haddad, "Paclitaxel and Pegylated-Liposomal Doxorubicin are Both Active in Angiosarcoma,” Cancer, Vol. 104, No. 2, 2005, pp. 361-366. doi:10.1002/cncr.21140

[11] J. T. Hartmann and S. Patel, "Recent Developments in Salvage Chemotherapy for Patients with Metastatic Soft Tissue Sarcoma,” Drugs, Vol. 65, No. 2, 2005, pp. 167178. doi:10.2165/00003495-200565020-00002

[12] R. Isogai, A. Kawada, Y. Aragane, et al., "Successful Treatment of Pulmonary Metastasis and Local Recurrence of Angiosarcoma with Docetaxel," Journal of Dermatology, Vol. 31, No. 4, 2004, pp. 335-341.

[13] M. L. Hensley, R. Maki, E. Venkatraman, et al., “Gemcitabine and Docetaxel in Patients with Unresectable Leiomyosarcoma: Results of a Phase II Trial,” Journal of Clinical Oncology, Vol. 20, No. 12, 2002, pp. 2824-2831. doi:10.1200/JCO.2002.11.050

[14] S. Okuno, J. Edmonson, M. Mahoney, et al., "Phase II trial of Gemcitabine in Advanced Sarcomas," Cancer, Vol. 94, No. 12, 2002, pp. 3225-3229. doi:10.1002/cncr.10602

[15] S. R. Patel, V. Gandhi, J. Jenkins, et al., "Phase II Clinical Investigation of Gemcitabine in Advanced Soft Tissue Sarcomas and Window Evaluation of Dose Rate on Gem- 
citabine Triphosphate Accumulation,” Journal of Clinical Oncology, Vol. 19, No. 15, 2001, pp. 3483-3489.

[16] K. M. Leu, L. J. Ostruszka, D. Shewach, et al., "Laboratory and Clinical Evidence of Synergistic Cytotoxicity of Sequential Treatment with Gemcitabine Followed by Docetaxel in the Treatment of Sarcoma," Journal of Clinical
Oncology, Vol. 22, No. 9, 2004, pp. 1706-1712. doi:10.1200/JCO.2004.08.043

[17] A. Minchom, R. L. Jones, C. Fisher, et al., "Clinical Benefit of Second-Line Palliative Chemotherapy in Advanced Soft-Tissue Sarcoma,” Sarcoma, 2010, Article ID: 264360. 